\title{
Performance of Charcoal Coconut Shell Ash in the Asphalt Mixture under Long Term Aging
}

\author{
Ramadhansyah Putra Jaya, Mohd Rosli Hainin, Khairil Azman Masri, Youventharan \\ Duraisamy, Ekarizan Shaffie
}

\begin{abstract}
Improvement in transportation system is never been as easy as just providing links for better connection and network but more to do with the pavement quality of the road itself. Modification with agriculture waste is just another approach to enhance the performance of asphaltic concrete. In this study, a non-traditional bitumen modifier from a coconut shell which is the charcoal coconut shell ash (CCSA) was used. Addition of CCSA in bitumen with $0 \%, 2 \%, 4 \%$, 6\%, and $8 \%$ by weight of bitumen were investigated along with the laboratory stimulation of aging was applied in this study. Properties of modified asphalt mixture were determined using resilient modulus, dynamic creep and Marshall Stability test.. Results of samples with CCSA which underwent aging show some improvement in terms of the stability and permanent deformation characteristics. Resilient modulus, dynamic creep and Marshall Stability tests recorded the highest rates when compared to controlled sample. Hence, for more durable asphalt concrete and high serviceability it is recommended to use $2 \%$ to $4 \%$ of CCSA.
\end{abstract}

Index Terms: Coconut Shell; Dynamic Creep; Marshall Stability; Resilient Modulus.

\section{INTRODUCTION}

Improvement in transportation system have moved forward from not just only by providing links for better connection and network but also enhancing the pavement quality of the road [1]. Roads in Malaysia mostly covered by flexible type pavement in normal construction practice [2]. However, in the long run problems arise especially in the quality of these types of pavements after several years of services like rutting, cracking, bleeding and permanent deformations [1]. Many researches have been carried out over the past decades to improve the quality of pavement by modifying the asphalt mixture $[3,4,5]$. This concept of modification is not common nowadays especially when the industry is foreseeing challenges with sustainable raw material and earth resources. The purpose of modifying the mixture is to obtain better properties and enhance the performance of asphaltic concrete. Generally any type of pavement in service will undergo aging process which will show some reduction in performance of the road. As such the bituminous sample exposed to actual environment, the

Revised Manuscript Received on October 22, 2019

Ramadhansyah Putra Jaya, Faculty of Civil Engineering Technology, Universiti Malaysia Pahang, Pahang, Malaysia

Mohd Rosli Hainin, Faculty of Civil Engineering Technology, Universiti Malaysia Pahang, Pahang, Malaysia

Khairil Azman Masri, Faculty of Civil Engineering Technology, Universiti Malaysia Pahang, Pahang, Malaysia

Youventharan Duraisamy, Faculty of Civil Engineering Technology, Universiti Malaysia Pahang, Pahang, Malaysia

Ekarizan Shaffie, Institute for Infrastructure Engineering \& Sustainable Management, Universiti Teknologi MARA, Selangor, Malaysia original characteristic of asphalt pavement will deplete over time. Due to these issues, motivation to enhance the pavement quality was encouraged among researchers by modified asphalt mixture with addition of natural additive.

Research on coconut shell as modifier in bitumen and aggregates replacement has caught attention amongst the researcher [6,7]. However, innovation in utilization of charcoal made of coconut shell is still uncommon and new in Malaysian construction industry. The addition of natural additive like charcoal coconut shell ash in asphalt mixture is very rare. Currently only a few studies are available on how the charcoal coconut shell ash could enhance the engineering properties of bitumen and asphaltic concrete [5]. Charcoal coconut shells have high lignin content in carbon structure which enhanced the durability and abrasion resistance properties [8]. Meanwhile Abdullah et al. [9] explained on how charcoal coconut shell ash affects the physical properties of bitumen with different size. The softening point value and penetration value indicates that the modified bitumen has better resistance and susceptible to temperature [10]. The properties of charcoal coconut shell ash itself show some good compatibility in comparison to bitumen and asphalt mixture hence making it a suitable material for road construction application.

According to Jeffry et al. [1] the physical and rheological properties of bitumen can be affected by the presence of nano-charcoal coconut-shell ash (NCA). Research conducted found out that the presence of $6 \%$ of nano-charcoal coconut-shell ash (NCA) content in aged specimen help to retard the aging process of bitumen. The modified bitumen with NCA also recorded higher rutting performance compared to other particles size [11]. From the literature study carried out, there is a clear evident of the potential of coconut shell ash in improving the asphaltic mixture performance by enhancing its properties. This study is also aimed to optimatize the waste material usage in pavement design, thus can provide some useful data on the charcoal coconut shell ash performance in asphalt mixture design. Findings from this study can be a reference to establish a new pavement mix design which will benefit in road pavement technology and help with waste materials management sector in Malaysia.

\section{MATERIALS AND METHODS}




\section{A. Bitumen}

Bitumen $60 / 70$ with $65 \mathrm{dmm}$ penetrations, $51{ }^{\circ} \mathrm{C}$ softening point, 1.03 relative density, and $600 \mathrm{cp}$ viscosity at $135^{\circ} \mathrm{C}$ was the main binder. The optimum bitumen content used in this investigation was selected at $5 \%$ within the design bitumen content range 4\% - 6\% as stated in Malaysian Public Works Department guideline [2].

\section{B. Aggregate and gradation}

The coarse aggregate was crushed granite stone where the fine aggregate used was natural river sand with the specific gravities of aggregates are 2.665 (coarse) and 2.715 (fine), respectively. The sizes of the granite aggregates fit the envelope for the Malaysian Public Works Department AC14 [2] as illustrated in Fig. 1. The median gradation was selected as the target gradation.

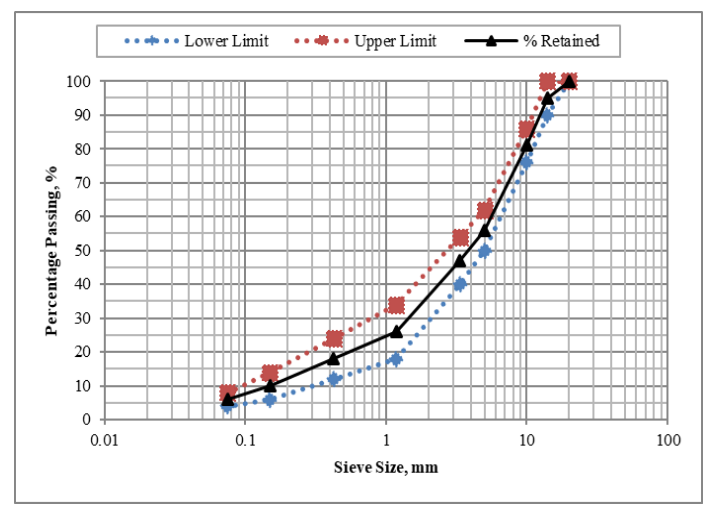

Fig. 1. Aggregate sizes used in this study [2]

\section{Coconut Shell Ash}

Coconut shells were sun dried to ease the removal of the coconut fibre. The shells were ripped out and washed from any unwanted substances. Coconut shells were subjected under heating process at $400-450{ }^{\circ} \mathrm{C}$ for five minute using furnace to change its properties to charcoal. Charcoal coconut shell was then left to cool down in room temperature before being crushed manually. Small sizes of crushed charcoal coconut shells were then grinded using LAAV with 1200 cycles until became ash in physically. Charcoal coconut shell ash (CCSA) was then sieved with requirement of passing BS sieve $0.075 \mathrm{~mm}$. CCSA was then weighted $2 \%$, $4 \%, 6 \%$, and $8 \%$ by the weight of bitumen for each of testing conducted.

\section{Mix Design}

As per requirement for this study the aggregate, binder, and CCSA were mixed thoroughly before being compacted at $160 \pm 0.5^{\circ} \mathrm{C}$. In order to mitigate disintegration, the samples were compacted with 75 blows using Marshall Hammer. Samples that have been removed from the mold were allowed to cooling before checking the stability value using BS EN 12697-34 [12] standard. Accordingly, the specimens were prepared for 45 minutes under water bath at $60 \pm 1{ }^{\circ} \mathrm{C}$. Eventually all the samples were tested at a constant deformation rate of $50.8 \mathrm{~mm} /$ minute until the maximum load was reached.

\section{E. Resilient Modulus Test}

The resilient modulus test according to ASTM D7369 [13] was used to measure the recoverable strain of the material under repeated stress of 1000 N. Sample was examined at 25 ${ }^{\circ} \mathrm{C}$ and $40{ }^{\circ} \mathrm{C}$ to simulate low and high temperature conditions and a repeated haversine load with five pulses was applied onto the sample at $90^{\circ}$ rotation.

\section{F. Dynamic Modulus Test}

Dynamic creep test was conducted in accordance with BS EN 12697 [14] at $40{ }^{\circ} \mathrm{C}$. In order to estimate the rutting potential of the asphalt mixture, $300 \mathrm{kPa}$ loading was applied until 3600 cycles. Creep stiffness modulus and creep strain slope were measured as the specimen deforms with time using Equations 1 and 2.

$$
\mathrm{E}=\sigma /(\varepsilon)
$$

$$
\mathrm{CSS}=\log \varepsilon 3600-\log \varepsilon 1200 / \log 3600-\log 1200
$$

Where $\mathrm{E}$ is creep stiffness modulus in $\mathrm{MPa}, \sigma$ was applied stress in $\mathrm{kPa}, \varepsilon$ is cumulative axial strain at 3600 cycles in $\mathrm{mm}$. CSS which is the creep strain slope was computed using $\varepsilon 3600$ strain value at 3600 cycles and $\varepsilon 1200$ strain value at 1200 cycles.

\section{G. Long term aging test}

Aging stimulation for asphalt mixture with CCSA adopted as described in ASSHTO R30-02 [15]. Asphalt mixture was placed in a pan immediately after mixing with even thickness around 25 to $50 \mathrm{~mm}$. Normally loose mixtures were pre-heated in an oven up to $135^{\circ} \mathrm{C} \pm 3^{\circ} \mathrm{C}$ for 4 hour \pm 5 minute before being stirred at every $60 \pm 5$ minute to maintain uniform conditioning. This is followed by a compaction procedure using Marshall Compactor at suitable temperature. Samples in this study were labeled "NA" for non-aging and "LTA" for long term aging.

\section{RESULTS AND DISCUSSION}

\section{A. Stability}

Fig. 2 shows the findings from the stability tests on asphalt mixtures. In was a clear trend in all cases, when the stability increases with CCSA content up to a maximum level before decreasing. Generally asphaltic material with higher stability values will behave stiffer and are more resistant. Figure 2 shows that the non-aging stability was found to range from 12326 to $13420 \mathrm{~N}$ where the stability value under the long term aging was about 12669 to $16435 \mathrm{~N}$. On the other hand, stability values increased after specimen was subjected to long term aging in all asphalt mixtures. It is known to some extend that the oxidation process do contribute to the increase of stability. For instance, at $0 \%$ CCSA, the stability of young asphalts mixtures was about $12653 \mathrm{~N}$ whereas under the long term aging mixture was approximately $15012 \mathrm{~N}$. There is a difference of more than $18.6 \%$ in terms of performance. However, at $2 \%$ CCSA, the stability of asphalt mixture for unaged and long term aging is $13152 \mathrm{~N}$ and $16435 \mathrm{~N}$,

respectively. Adding 2\% CCSA to the asphalt mixture can increase stability by up to $9.5 \%$. The results also indicate that $4 \%$ CCSA asphalt mixture exhibited

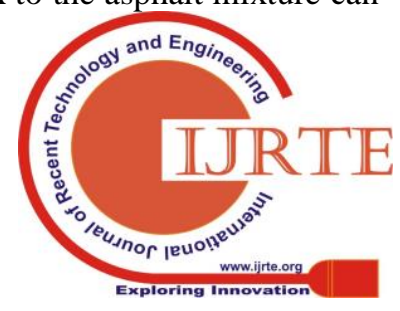


the highest stability at unaged conditions while 2\% CCSA asphalt mixture showed the maximum stability in long term aged. Generally, at $8 \%$ CCSA, the stability decreases to a value lower than that of control mixture ( $0 \%$ CCSA). There is a clear indication that the use of $4 \%$ and $2 \%$ CCSA in asphalt mixture was more effective in enhancing stability under the unaged and long term aged specimen.

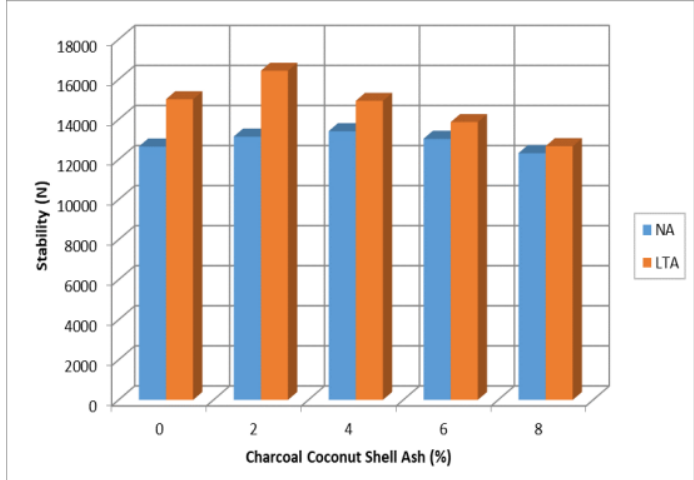

Fig. 2 Asphaltic concrete stability with different percentage of CCSA

\section{B. Flow}

The flow performance of asphalt mix at different percentage of CCSA is illustrated in Fig. 3. The asphalt mixture produced inconsistent flow value when exposed to non-aging condition with the flow of sample to be in the range of approximately $3.7 \mathrm{~mm}$ to $4.2 \mathrm{~mm}$. Initially there was an increase in flow when 0 to $6 \%$ CCSA content sample was exposed to long term aging before decreasing with $8 \%$ CCSA. The sample increased from $3.70 \mathrm{~mm}$ to $3.95 \mathrm{~mm}$ when the CCSA percentage increases from 0 to $6 \%$. However, the flow value at $8 \%$ CCSA was about $3.30 \%$. According to JKR specification [2], the flow values for the purpose of surfacing and pavement under heavy traffic category should be in the range from $3 \mathrm{~mm}$ to $5 \mathrm{~mm}$. There is a need for immediate study to know the effect of asphalt mixture with agricultural waste materials to accommodate the existing specification outlined by JKR [2].

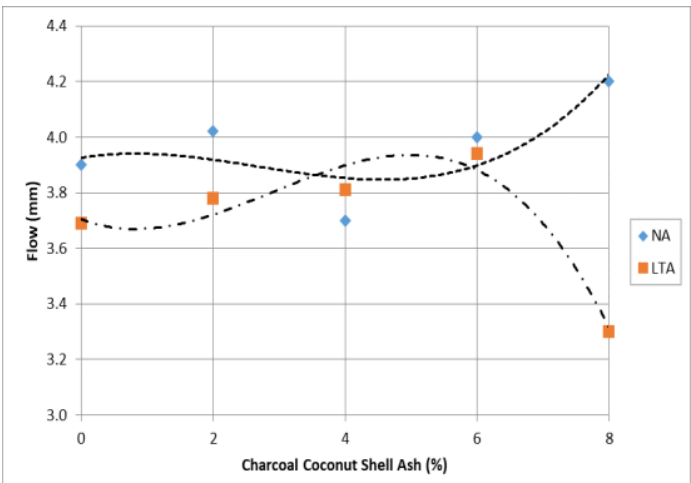

Fig. 3 Asphaltic concrete flow with different percentage of CCSA

\section{Stiffness}

Figure 4 showcase the stiffness performance of the asphalt mixture under aging conditions with increasing CCSA content. The test results were consistent as the controlled mixtures in all conditions were less stiff than asphalt mixtures with CCSA. Theoretically the oxidation process that took place during the mixing and the curing stage is known to improve the stiffness of the asphaltic concrete mixture. The
4\% CCSA of mixture under non aging condition and LTA exhibited the highest stiffness value compared to controlled sample (0\%), CCSA 2\%, CCSA 5\%, and CCSA $8 \%$. Thus, $4 \%$ addition of CCSA with virgin bitumen is considered as the optimal limit for both conditions. It can be said that the use of $4 \%$ CCSA as the contents in asphalt mixtures was more effective in enhancing stiffness.

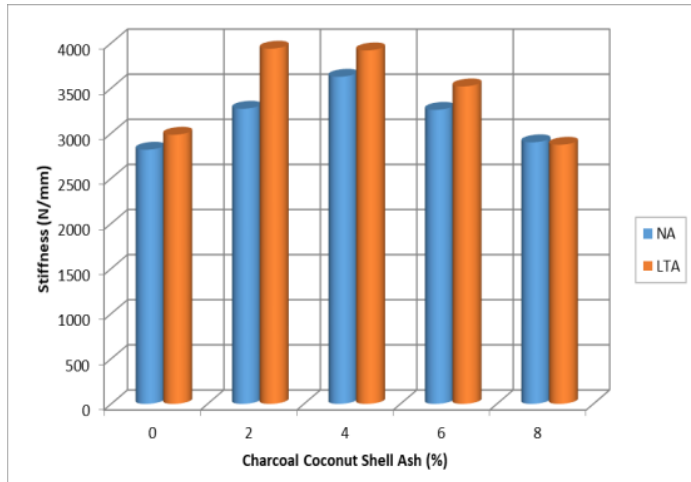

Fig. 4 Asphaltic concrete stiffness with various percentage of CCSA

\section{Voids filled with Bitumen (VFB)}

Figure 5 shows the correlation between voids filled with bitumen (VFB) and CCSA content at different aging condition. When the specimens were subjected to the long term aging, the VFB of asphalt mixture initially starts to increase, before decreasing with $8 \%$ of CCSA. The maximum VFB was achieved when the CCSA content was increased up to $8 \%$. However, when the specimens of unaged condition were tested, the VFB of the asphalt mixture containing CCSA was approximately $80 \%-87 \%$. For general practice, 3 to $5 \%$ bitumen is added to achieve a mixture with VFB in the range of 75 to $85 \%$ [2]. Again there is no specific guideline given in the usage of waste materials in the bitumen mixture.

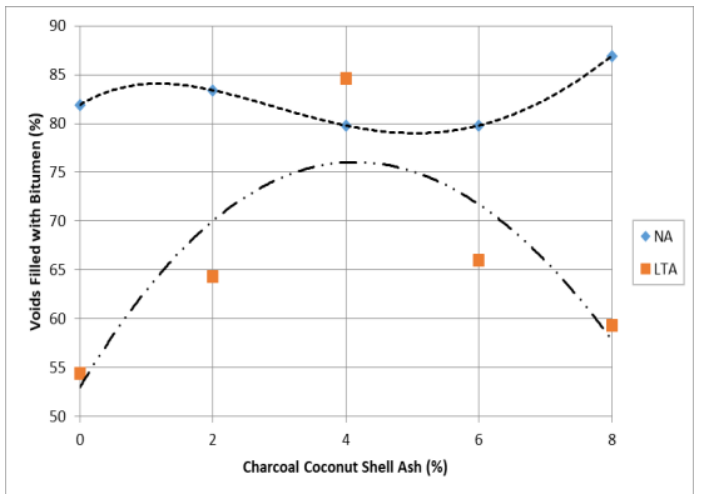

Fig. 5 VFB of asphaltic concrete with various percentage of CCSA

\section{E. Voids in Total Mix (VTM)}

Generally, the void in total mix (VTM) of CCSA asphalt mixtures initially increased during the percentage of CCSA

increases from $0 \%$ to $4 \%$ and then started to decrease until it reaches the $8 \%$ CCSA level as presented in Fig. 6 .

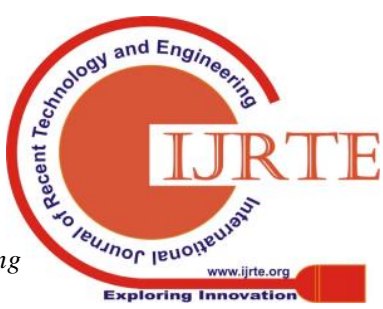


For example, at the non-aging condition, the VTM of the asphalt mixtures increased from $2.3 \%$ to $3.5 \%$ when the CCSA content increases within the region of $0 \%$ to $4 \%$. However, at $6 \%$ and $8 \%$ of CCSA content, the VTM of the asphalt mixtures was decreasing gradually. At all aging condition, the $4 \%$ CCSA mixtures exhibits the highest VTM followed by CCSA-0, CCSA-2, CCSA-6 and CCSA-8, respectively. In record the lowest voids in total mix was achieved with $8 \%$ of CCSA. According to Abu Bakar et al. [16] in the case of low air voids there is a high chance of reducing the aging process of asphalt films. Hence aggregate mass which is coated with this asphalt will reduce the penetration of water and asphalt stripping can be minimized too.

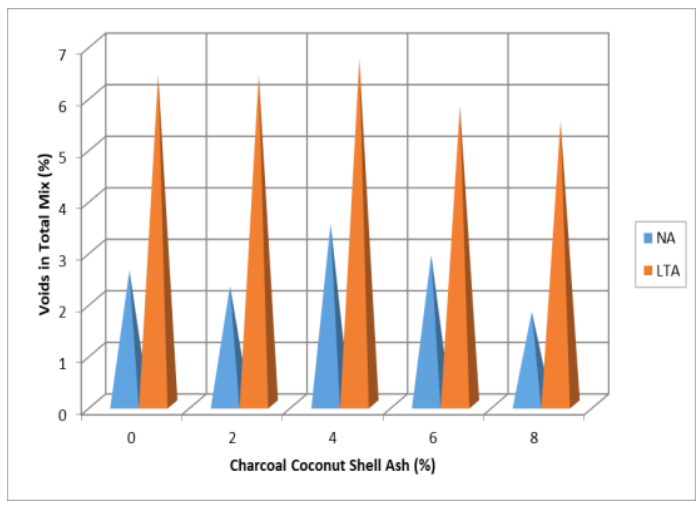

Fig. 6 VTM of asphaltic concrete with various percentage of CCSA

\section{F. Resilient Modulus}

Fig. 7 showcases the resilient modulus performance of the asphalt mixtures with various amounts of CCSA and under the varying aging condition. Significant findings from this test as such that the resilient modulus of asphaltic concrete incorporating CCSA content was higher at the temperature of $25^{\circ} \mathrm{C}$ than the $40^{\circ} \mathrm{C}$ at all age. When the temperature was $25^{\circ} \mathrm{C}$ to $40^{\circ} \mathrm{C}$, the resilient modulus of NA specimens was reduced by approximately $80 \%$ to $87 \%$. Similarly $85 \%$ of reduction was seen in the resilient modulus of CCSA mixtures under LTA in the same temperature. The test results also demonstrated that in long term aging experiment the asphalt mixture with CCSA recorded the highest resilient modulus compared to unaged specimen. The amount of increment in resilient modulus of specimens subjected to long term aging due to the effect of CCSA will be offsetting the hardening effect of aging.

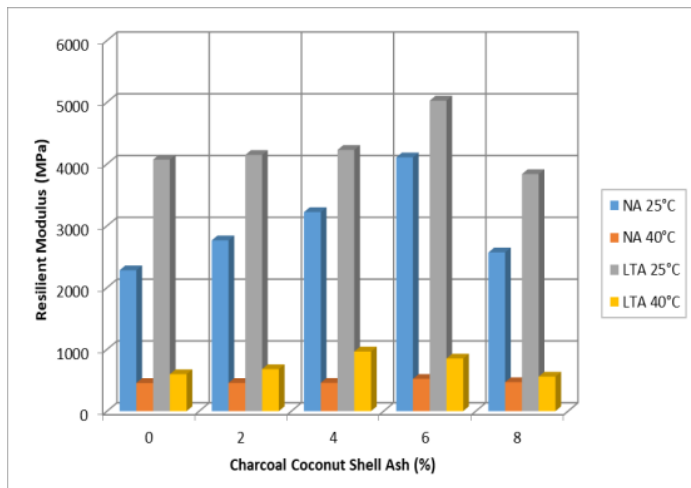

Fig. 7 Asphaltic concrete resilient modulus with different percentage of CCSA

\section{G. Dynamic Creep}

The general effects of CCSA asphalt mixtures on the creep modulus are graphically presented in Fig. 8. The results show that aging causes CCSA asphalt mixtures to exhibit higher resistant against rutting. Age hardening of the binder causes some increment in creep modulus after long term aging. For instance, for non-aging specimens, the creep stiffness of asphalt mixtures increases from $168 \mathrm{MPa}$ to $428 \mathrm{MPa}$ when CCSA content increases from $0 \%$ to $8 \%$. However, after long term aging, the dynamic creep of the mixture was increasing from $214 \mathrm{MPa}$ to $484 \mathrm{MPa}$ as the CCSA content increased from $0 \%$ to $8 \%$.

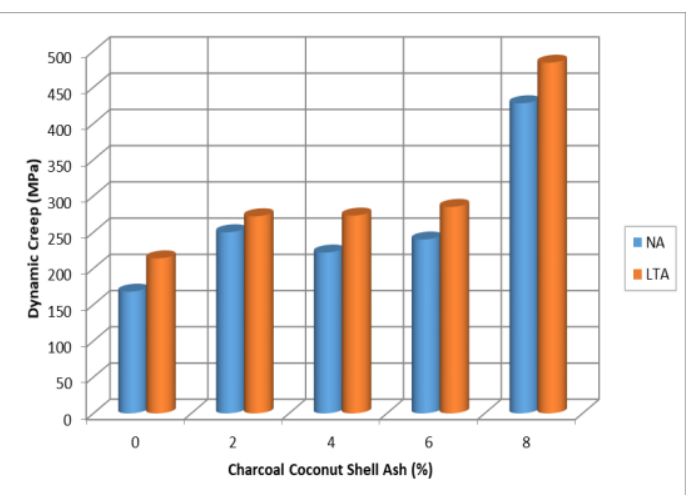

Fig. 8 Creep stiffness of asphaltic concrete at different percentage of CCSA

\section{CONCLUSION}

From the overall experimental results obtained and observations made, the presence of coconut shell ash charcoal significantly affected the performance of asphaltic concrete under long term service. Adding of charcoal coconut shell ash at different percentage shows significant effect on the stability, flow and stiffness of the asphalt mixtures under the long term aging. Incorporating charcoal coconut shell ash also enhances the performance of asphaltic concrete when the modulus and creep stiffness increases gradually. Approximately $2 \%$ to $4 \%$ of charcoal coconut shell ash in asphalt mixture will exhibit higher stability compared to other amount.

\section{ACKNOWLEDGMENT}

The support provided by the Malaysian Ministry of Higher Education and Universiti Malaysia Pahang in the form of a research grant (RDU/UMP) vote number RDU1803157 and RDU1803160 for this study is highly appreciated.

\section{REFERENCES}

1. Jeffry S.N.A., R.P. Jaya, N. Abdul Hassan, H. Yaacob, J. Mirza, S.H. Drahman, Effects of nanocharcoal coconut-shell ash on the physical and rheological properties of bitumen, Constr. Build. Mater. 158 (2018) 1-10.

2. Jabatan Kerja Raya Malaysia (JKR). Standard Specification for Road Works, Section 4: Flexible Pavement. No. JKR/SPJ/2008-S4, pp. S4-58-S4-69.

3. Mohd Ibrahim M.Y., P.J. Ramadhansyah, H. Mohd Rosli, M.H. Wan Ibrahim, M. N. Fadzli, Utilization of nano silica as cement paste in mortar and porous concrete pavement, Adv. Mater. Res. 1113 (2015) $135-139$.

4. Wan Azahar W.N.A., R.P. Jaya, M.R. Hainin, M. Bujang, N. Ngadi, Mechanical performance of asphaltic concrete

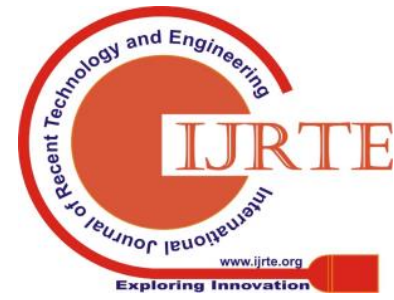


incorporating untreated and treated waste cooking oil, Constr. Build. Mater. 150 (2017) 653-663.

5. Manap N., R. Putra Jaya, S.N.A. Jeffry, N.A. Miron, N. Abdul Hassan, M.R. Hainin, C.N. C.W. The effect of coconut shell on engineering properties of porous asphalt mixture, J. Teknol. 78 (7-2) (2016) 127-132.

6. Sarki J., S.B. Hassan, V.S. Aigbodion, J.E. Oghenevweta, Potential of using coconut shell particle fillers in eco-composite materials, J. Alloys Compd. 509 (5) (2011) 2381-2385.

7. Ouyang S., S. Xu, N. Song, S. Jiao, Coconut shell-based carbon adsorbents for ventilation air methane enrichment, Fuel 113 (2013) (2013) 420-425.

8. Gunasekaran K., P.S. Kumar, M. Lakshmipathy, Mechanical and bond properties of coconut shell concrete, Constr. Build. Mater. 25 (1) (2011) 92-98.

9. Abdullah, M.E., Mad Rosni, N.N., Jaya, R.P., Yaacob, H., Hassan, N.A. and Agussabti (2017). Effect of Charcoal Ash Coconut Shell from Waste Material at Different Size on the Physical Properties of Bitumen. Key Engineering Materials. 744(April), 121-125.

10. Yaacob, H., Hainin, M.R., Safuan, A. and Chang, F.L. (2014) Information for the Malaysian asphalt industry towards better pavement interlayer bonding. Sains Malaysiana. 43(3), 467-474.

11. Raja Zulkefli, R.N.A., Yaacob, H., Putra Jaya, R., Warid, M.N.M., Hassan, N., Hainin, M.R. and Idham, M.K (2018). Effect of different sizes of palm oil fuel ash (POFA) towards physical properties of modified bitumen. IOP Conference Series: Earth and Environmental Science. 140(1), pp. 1-7.

12. BS EN 12697-30:2012. Bituminous mixtures. Test methods for hot mix asphalt. Specimen preparation by impact compactor. BSI Standards Institution, London, UK.

13. ASTM D7369-11. Standard Test Method for Determining the Resilient Modulus of Bituminous Mixtures by Indirect Tension Test. American Society for Testing and Materials, West Conshohocken, PA, United States.

14. BS EN 12697-25:2016. Bituminous mixtures. Test methods. Cyclic compression test. BSI Standards Institution, London, UK.

15. AASHTO R 30-02. 2015. Standard Practice for Mixture Conditioning of Hot-Mix Asphalt (HMA). American Association of State and Highway Transportation Officials, USA.

16. Abu Bakar S.K., M.E. Abdullah, M. Mustafa Kamal, R. Abd Rahman, R. Putra Jaya, R. Buhari, K.A. Hadithon. Influence of ageing process on rheological characteristic of waste natural rubber latex modified bitumen. IOP Conf. Series: Journal of Physics: Conf. Series 1049 (2018) 1-6. 